\title{
The malaria burden of Amerindian groups of three Venezuelan states: a descriptive study based on programmatic data
}

\author{
Juan C. Gabaldón-Figueira ${ }^{1,2^{*}}$, Carlos Chaccour ${ }^{3,1,4}$, Jorge Moreno ${ }^{5}$, Maria Villegas ${ }^{6,7}$ and Leopoldo Villegas $s^{6,7}$
}

\begin{abstract}
Background: Fifty-three percent of all cases of malaria in the Americas in 2019 came from Venezuela, where the epidemic is heavily focused south of the Orinoco river, and where most of the country's Amerindian groups live. Although the disease is known to represent a significant public health problem among these populations, little epidemiological data exists on the subject. This study aims to provide information on malaria incidence, geospatial clustering, and risk factors associated to Plasmodium falciparum infection among these groups.

Methods: This is a descriptive study based on the analysis of published and unpublished programmatic data collected by Venezuelan health authorities and non-government organizations between 2014 and 2018. The Annual Parasite Index among indigenous groups (API-i) in municipalities of three states (Amazonas, Bolivar, and Sucre) were calculated and compared using the Kruskal Wallis test, risk factors for Plasmodium falciparum infection were identified via binomial logistic regression and maps were constructed to identify clusters of malaria cases among indigenous patients via Moran's I and Getis-Ord's hot spot analysis.
\end{abstract}

Results: 116,097 cases of malaria in Amerindian groups were registered during the study period. An increasing trend was observed between 2014 and 2016 but reverted in 2018. Malaria incidence remains higher than in 2014 and hot spots were identified in the three states, although more importantly in the south of Bolivar. Most cases (73.3\%) were caused by Plasmodium vivax, but the Hoti, Yanomami, and Eñepa indigenous groups presented higher odds for infection with Plasmodium falciparum.

Conclusion: Malaria cases among Amerindian populations increased between 2014 and 2018 and seem to have a different geographic distribution than those among the general population. These findings suggest that tailored interventions will be necessary to curb the impact of malaria transmission in these groups.

Keywords: Malaria, Venezuela, Amerindian groups, Amazonas, Bolivar, Sucre

\section{Background}

Malaria is a major public health concern in the Americas, where 889,000 cases and 550 deaths were estimated to have occurred in 2019. Fifty-three percent of these cases, and $73 \%$ of all deaths came from Venezuela, where

\footnotetext{
*Correspondence: jgabaldonfi@unav.es

1 Área de Enfermedades Infecciosas, Clínica Universidad de Navarra, 31008 Pamplona, Spain

Full list of author information is available at the end of the article
}

incidence has increased over $1000 \%$ in the last two decades, amidst a context of economic crisis and political unrest [1]. The disease disproportionally affects regions south of the Orinoco River, where cases are clustered in the Sifontes municipality, of the Bolivar State [2]. There is a significantly lesser burden in the northeast coast of the country [3]. By 2016, the last year with detailed public epidemiological data, only the three states of Bolívar, Amazonas (south of the country) and Sucre (northeast) accounted for $90 \%$ of all registered cases [4]. Plasmodium 
vivax causes $77 \%$ of all registered cases, followed by Plasmodium falciparum, with $16 \%$, and mixed infections (6.5\%). Plasmodium malariae is rare and underdiagnosed [1].

The total Amerindian population in Venezuela was estimated to surpass 720,000 people in 2011 [5], most of which are concentrated in malaria-endemic regions. According to the last available census data, approximately $70 \%$ of the 76,000 Amerindians in Amazonas state lived in a rural environment. A similar picture is seen in Bolivar (79\% of a 54,600 population). In Sucre, however, $60 \%$ of the 22,200 indigenous inhabitants lived in urban areas. Amerindians in Venezuela are mostly young, with a median age of 21 years, and $65 \%$ of the population are under 30 years old [5].

These indigenous groups have historically had poor access to healthcare services. In some remote areas primary healthcare and epidemiological surveillance of malaria and other infectious diseases is practiced by specially trained local community agents $[6,7]$. Apart from this, these communities lack permanent access to other medical services. This, as well as the expansion of illegal mining across their territories, makes them particularly vulnerable to malaria $[8,9]$.

Epidemiological studies in other endemic regions of South America have demonstrated that malaria transmission in indigenous communities responds to epidemiological factors different to those in the general population [10]. Moreover, the increasingly important influence of illegal mining in said transmission dynamics has not been studied in detail and has been traditionally limited to a few settlements along the Caura River basin $[7,9,11]$. Before the COVID-19 pandemic, economic crisis had increased mobility of the general population, and likely of indigenous groups, to mines south of the country, and to Colombia, and Brazil [12]. More recently yet, restrictions caused by COVID-19 and increasingly common fuel shortages might have impeded social mobility.

Apart from a few studies evaluating the efficacy of insecticide-treated hammocks [13], and the limited distribution of bed nets in some communities [7], there are no vector control interventions that specifically target malaria transmission within indigenous communities.

This work analyses published, and unpublished epidemiological records collected by Venezuelan health authorities and non-government organizations (NGOs) between 2014 and 2018. The aim is to provide information on the general burden of malaria among the indigenous people of Amazonas, Bolivar, and Sucre states, describe differences in regional incidence, spatial clustering, risk factors for infection with Plasmodium falciparum, and transmission seasonality.

\section{Methods}

This is a descriptive study based on the analysis of programmatic data collected by Venezuelan health authorities and NGOs in three Venezuelan states. Morbidity data from 2014 to 2017 was obtained from publicly available sources. These included the 2014, 2015, and 2016 Epidemiological Bulletins published by the Venezuelan Ministry of Popular Power for Health (MPPS), which present aggregated parish-level (administrative level 4) on malaria morbidity for every state $[4,14,15]$, as well as the Pan-American Health Organization's (PAHO) malaria surveillance dataset [16]. Data from 2018, as well as the ethnicity of individual cases reported during the studied period were retrieved from raw datasets and unpublished reports collected by local volunteers, and Ministry of Health's staff (unpublished datasets, Venezuelan Ministry of Health). These datasets include names, ID numbers, age, gender, address, likely place and date of infection, place of diagnosis, identified Plasmodium species, occupation, and ethnicity of individual patients, and are routinely collected as part of a national passive malaria surveillance programme.

As per national guidelines, only symptomatic patients seeking care at a public health facility are tested, either with thin and thick blood films, or a rapid diagnostic test (RDT). Only new cases are included in registries, and are defined by the Venezuelan Health Ministry as any symptomatic infection with a positive test occurring 90 days or more since the completion of a treatment scheme [17]. Nonetheless, parasites are not regularly genotyped, which hampers differentiation of true new cases from relapses, given the high prevalence of Plasmodium vivax. Cases not meeting these criteria are considered relapses, typically removed, and stored separately by staff of the national malaria control programme.

Datasets from Amazonas, Bolivar, and Sucre were merged, and filtered to exclude patients not belonging to any of the Amerindian groups listed in the Venezuelan Ministry of Health's registries (Additional file 1). They were then categorized based on the state of probable infection. Cases originating from states other than Amazonas, Bolivar, or Sucre were excluded from the analysis.

These data were used to estimate the risk of malaria among indigenous groups at different locations, calculating the Annual Parasite Index (API-i) at the municipality level (administrative level 3). For this, the annual cumulative malaria incidence in Amerindian patients was divided by the estimated Amerindian population of each state and municipality and multiplied by 1000 . These results were compared using a Kruskal-Wallis test. The indigenous population of municipalities was estimated based on data from the last available census 
and using a geometric growth method, based on the following formula [18].

$$
\begin{gathered}
P_{n}=P_{0}\left(1+R_{G}\right)^{n} \\
R_{G}=\frac{\ln \left(\frac{P_{0}}{P_{0-1}}\right)}{T}
\end{gathered}
$$

where $P_{n}$ represents the estimated population at any time, $n$ is the time in years between the last available census and the time of estimation, $P_{0}$ the size of the population in the last available census, $P_{0-1}$ the population size at the second last available census, $R_{G}$ is the estimated rate of growth and $T$ represents the time between the last two available censuses.

Incidence trends were plotted fitting a local regression (LOESS) curve with an $\alpha$ smoothing factor of 0.8 into monthly time series of cases. Malaria risk for indigenous and non-indigenous inhabitants of each state and municipality was compared using relative risk (RR):

$$
R R=\frac{a / b}{c / d}
$$

where $a$ represents malaria cases among Amerindian patients, $b$ is the total estimated Amerindian population, $c$ represents malaria cases among non-Amerindian patients, and $d$ is the estimated non-Amerindian population. Significance was tested using a z-test.

Spatial autocorrelation of cases was determined based on the likely place of infection of individual patients, and using the global Moran's I. Given a series of geographic entities, and an attribute associated to each one, this test evaluates if such attribute presents in a clustered, dispersed, or random pattern; with positive $I$ values indicating clustering. This test, however, fails to pinpoint individual clusters, and is of limited value when the spatial pattern is not homogenously distributed [19]. Thus, individual clusters of high (hot spots) and low (cold spots) infection burden were also mapped applying the Getis-Ord's Gi* statistic to reported parishes of infection, except in Amazonas, where it was applied to municipalities, due to the lack of adequate parish-level data. This test compares the mean number of local cases in a geographical unit and its neighbours, to the global mean, assigning a $p$ and $z$ value to each one. Large positive $z$ values and small $p$ values indicate a significant hot spot, while large negative $z$ values and small $p$ values suggest a significant cold spot [20].

The significance of clustering was determined with a $z$-score and parishes were classified based on it: confidence $90 \%(0.1>p>0.05)$, confidence $95 \%$ $(0.05>p>0.01)$ and confidence $99 \%(p<0.01)$, as done in similar studies [20,21].

The proportion of malaria cases caused by different Plasmodium species was compared using the Chi-square test. Odds ratios in univariate and multivariable models for $P$. falciparum vs $P$. vivax infection were calculated via binomial logistic regression and $p$ values determined via Wald's test.

Data analysis and processing was performed using Excel 2016 (Microsoft, Richmond, Virginia), SPSS 25 (IBM, Armonk, New York) and RStudio V 1.3.1093 (RStudio Team, Boston, Massachusetts). ArcGIS Pro 24 (Esri, Redlands, California) was used to construct maps and perform spatial analysis. Significance was set at 0.05 .

\section{Results}

Malaria incidence among indigenous communities in Amazonas, Bolivar and Sucre

A total of 116,097 new cases of malaria were registered in the 2014-2018 period among Amerindians. Of these, 62,267 (53.6\%) were male and 53,830 (46.4\%) female. Median age was 19 years (IQR: 9-31 years, Fig. 1), and $85 \%$ of all patients were under 40 years old.

Studied patients belonged to 39 different ethnic groups. However, only nine accounted for $91 \%$ of cases. These are: Pemon (27.3\%), Jivi (25\%), Piaroa/Wotjuja (16.1\%), Yekuana (8.9\%), Kurripaco (3.9\%), Eñepa (2.9\%), Piapoko (2.9\%), Yanomami (2.8\%) and Baré (1.3\%). Demographic characteristics of individual Amerindian groups are summarized in Table 1.

Most cases were registered in Amazonas (56.6\%) followed by Bolivar (43.2\%) and Sucre $(0.25 \%)$. The year with the highest number of new malaria cases was 2017 with 30,976.

\section{Amazonas state}

Most patients belonged to ethnic groups located in the north of the state, namely, Jivi (39.8\%), Wotjuja (25\%) and Yekuana (9.1\%). The number of new malaria cases in indigenous communities in $2018(21,530)$, was $174.2 \%$ higher than compared to the 2014 baseline (7852). An increasing trend in the number of monthly cases was observed between January 2016 and January 2018, when cases started to decrease (Fig. 2A). Despite this, the relative malaria risk for indigenous people compared to the non-indigenous population fell from 2.44 in 2014 $(p<0.01)$, to $0.89(p<0.01)$ in 2018 (Table 2). Cases in Amazonas were typically higher between January and June, but a clear seasonal pattern was not observed (Fig. 1B), and no significant differences were seen in the median number of monthly cases during the study period $(p=0.57$, Additional file 5). 


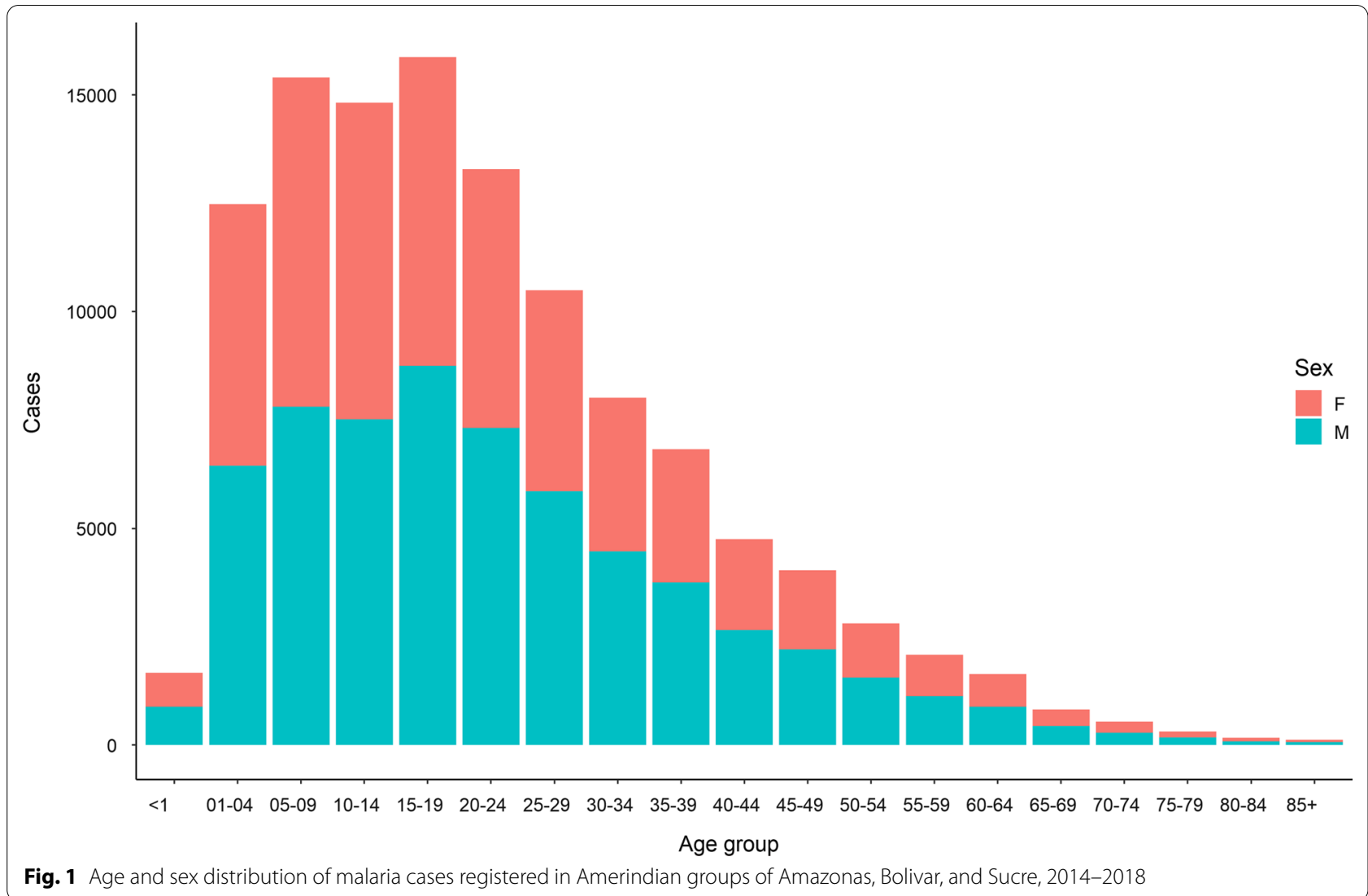

At municipal level, the Atures municipality accounted for most cases during the five-year study period (55.28\%). There was a significant difference in the median incidence of municipalities $(p<0.01)$, with the highest median API-i registered in Manapiare: 249.05 (IQR:151.25-301.64, Fig. 3, Additional file 2).

\section{Bolivar state}

The Pemon, the most numerous ethnic group in the state, accounted for $63.2 \%$ of all cases in Bolivar, followed by the Yekuana (8.7\%) and the Eñepa (6.6\%). As in Amazonas, malaria cases increased during the study period, compared to the 2014 baseline (7854), but particularly in $2016(15,676)$. From this point on, incidence reduced, reaching 8565 cases in 2018, 9.05\% more than in 2014 (Fig. 2C). Compared to that in the rest of the population, malaria risk for indigenous people was consistently higher in Bolivar: RR: 3.39 in 2014 ( $p<0.01), 2.47$ in 2015 $(p<0.01), 2.80$ in $2016(p<0.01), 1.11$ in $2017(p<0.01)$ and 1.02 in $2018(p=0.04$, Table 2). A seasonal pattern seems more patent in this state, as cases peak between February and April, and start declining from June onwards (Fig. 2C, D). There was a significant difference in the median number of monthly cases throughout the five-year period $(p<0.01)$.
At municipal level, almost a quarter of all cases originated in the Gran Sabana municipality (24.2\%), followed by Angostura (formerly known and noted in maps as Raul Leoni, 23.3\%) and Cedeño (20.4\%) municipalities. Incidence in the study period was significantly different between municipalities $(p=0.012)$, with the highest median API-i registered in El Callao: 575.76 cases per 1000 indigenous people (IQR: 457.14-1205.88). This, however, is probably a result of the extremely small projected indigenous population in the municipality (Additional file 3). Angostura had the highest median API-i of all municipalities with 100 indigenous inhabitants or more (310.84, IQR: 207.81-334.57, Fig. 3, Additional file 2).

\section{Sucre state}

The Warao accounted for 228 cases (78.4\%), followed by the Uruak (10\%), and the Puinave (7.2\%). Although the number of cases remained considerably lower than in Amazonas and Bolivar, it increased from zero in 2014 and 2015 to 140 in 2017, followed by a 72\% reduction in 2018 (39 cases). Annual incidence peaked in 2017 (5.75 cases per 1000 indigenous people), and then reduced to 1.58 in 2018 (Fig. 2E, Table 2). 
Table 1 Distribution of cases of malaria among Amerindian groups by sex, origin of infection, and ethnicity, 2014-2018

\begin{tabular}{|c|c|c|c|c|c|c|c|c|c|}
\hline Group & Female & Male & $\mathrm{Am}$ & Bol & Su & Total & (\%) & Median age & IQR \\
\hline Akawayo & 215 & 748 & 2 & 961 & 0 & 963 & 0.8 & 28 & 13 \\
\hline Amorua & 1 & 0 & 0 & 0 & 1 & 1 & 0 & 29 & (NA) \\
\hline Añu & 0 & 1 & 0 & 1 & 0 & 1 & 0 & 11 & (NA) \\
\hline Arawak & 12 & 37 & 3 & 45 & 1 & 49 & 0 & 27 & 30 \\
\hline Baniva & 487 & 523 & 997 & 13 & 0 & 1010 & 0.9 & 31 & 28 \\
\hline Baré & 632 & 857 & 1464 & 25 & 0 & 1489 & 1.3 & 30 & 27 \\
\hline Barí & 1 & 0 & 1 & 0 & 0 & 1 & 0 & 31 & (NA) \\
\hline Chirichano & 2 & 0 & 0 & 2 & 0 & 2 & 0 & 22 & 5 \\
\hline Eñepa & 1625 & 1702 & 16 & 3310 & 1 & 3327 & 2.9 & 15 & 22 \\
\hline Guanono & 34 & 23 & 56 & 1 & 0 & 57 & 0 & 17 & 20 \\
\hline Hoti & 501 & 441 & 443 & 498 & 1 & 942 & 0.8 & 9 & 18 \\
\hline Inga & 26 & 30 & 17 & 39 & 0 & 56 & 0 & 29 & 24 \\
\hline Japreria & 1 & 1 & 1 & 1 & 0 & 2 & 0 & 19 & 5 \\
\hline Jivi & 14,219 & 14,773 & 26,112 & 2880 & 0 & 28,992 & 25 & 17 & 21 \\
\hline Kariña & 742 & 724 & 0 & 1459 & 7 & 1466 & 1.3 & 14 & 19 \\
\hline Kubeo & 13 & 16 & 25 & 4 & 0 & 29 & 0 & 20 & 24 \\
\hline Kuiva & 1 & 2 & 3 & 0 & 0 & 3 & 0 & 53 & 37 \\
\hline Kurripaco & 2152 & 2418 & 4449 & 121 & 0 & 4570 & 3.9 & 23 & 24 \\
\hline Mako & 489 & 556 & 1043 & 2 & 0 & 1045 & 0.9 & 17 & 19 \\
\hline Panare & 27 & 30 & 57 & 0 & 0 & 57 & 0 & 15 & 25 \\
\hline Pemon & 13,119 & 18,571 & 4 & 31,685 & 1 & 31,690 & 27.3 & 20 & 21 \\
\hline Piapoko & 1582 & 1730 & 2313 & 999 & 0 & 3312 & 2.9 & 16 & 18 \\
\hline Piaroa/Wotjuja & 9019 & 9691 & 16,424 & 2286 & 0 & 18,710 & 16.1 & 20 & 21 \\
\hline Puinave & 560 & 616 & 1139 & 16 & 21 & 1176 & 1 & 21 & 25 \\
\hline Pume & 1 & 4 & 4 & 1 & 0 & 5 & 0 & 37 & 39 \\
\hline Saliva & 236 & 293 & 513 & 16 & 0 & 529 & 0.5 & 21 & 23 \\
\hline Sanema & 541 & 592 & 93 & 1040 & 0 & 1133 & 1 & 14 & 19 \\
\hline Sape & 1 & 1 & 2 & 0 & 0 & 2 & 0 & 18 & 15 \\
\hline Timotocuica & 1 & 1 & 1 & 1 & 0 & 2 & 0 & 22 & 42 \\
\hline Uruak & 14 & 16 & 1 & 0 & 29 & 30 & 0 & 17 & 24 \\
\hline Wanai & 91 & 85 & 64 & 112 & 0 & 176 & 0.1 & 27 & 25 \\
\hline Warao & 193 & 211 & 1 & 175 & 228 & 404 & 0.3 & 15 & 21 \\
\hline Warekena & 173 & 144 & 315 & 1 & 1 & 317 & 0.3 & 23 & 24 \\
\hline Wayuu & 10 & 19 & 12 & 17 & 0 & 29 & 0 & 22 & 25 \\
\hline Yanomami & 1621 & 1633 & 3199 & 55 & 0 & 3254 & 2.8 & 9 & 15 \\
\hline Yebarana & 142 & 118 & 259 & 1 & 0 & 260 & 0.2 & 20 & 22 \\
\hline Yekuana & 5037 & 5323 & 6001 & 4359 & 0 & 10,360 & 8.9 & 19 & 21 \\
\hline Yeral & 306 & 337 & 640 & 3 & 0 & 643 & 0.6 & 27 & 25 \\
\hline Yukpa & 3 & 0 & 1 & 2 & 0 & 3 & 0 & 18 & 39 \\
\hline Total & 53,830 & 62,267 & 65,675 & 50,131 & 291 & 116,097 & 100 & 19 & 22 \\
\hline
\end{tabular}

Am Amazonas, Bol Bolivar, Su Sucre, IQR Interquartile range

At municipal level, Benitez registered the highest API-i of the state (174.52, IQR: 0-174.52), however, this difference was not significant $(p=0.06)$ when municipalities with an indigenous population below 100 were excluded from the analysis. There is no evident seasonal pattern in Sucre (Fig. 2F).
The origin (place of likely infection) of malaria cases registered in 2014 (2016 for Sucre) and 2018 was mapped to compare changes in geographic clustering. Maps were constructed to the parish level (fourth administrative level) in Bolivar and Sucre, and to the municipality level (third administrative level) in 

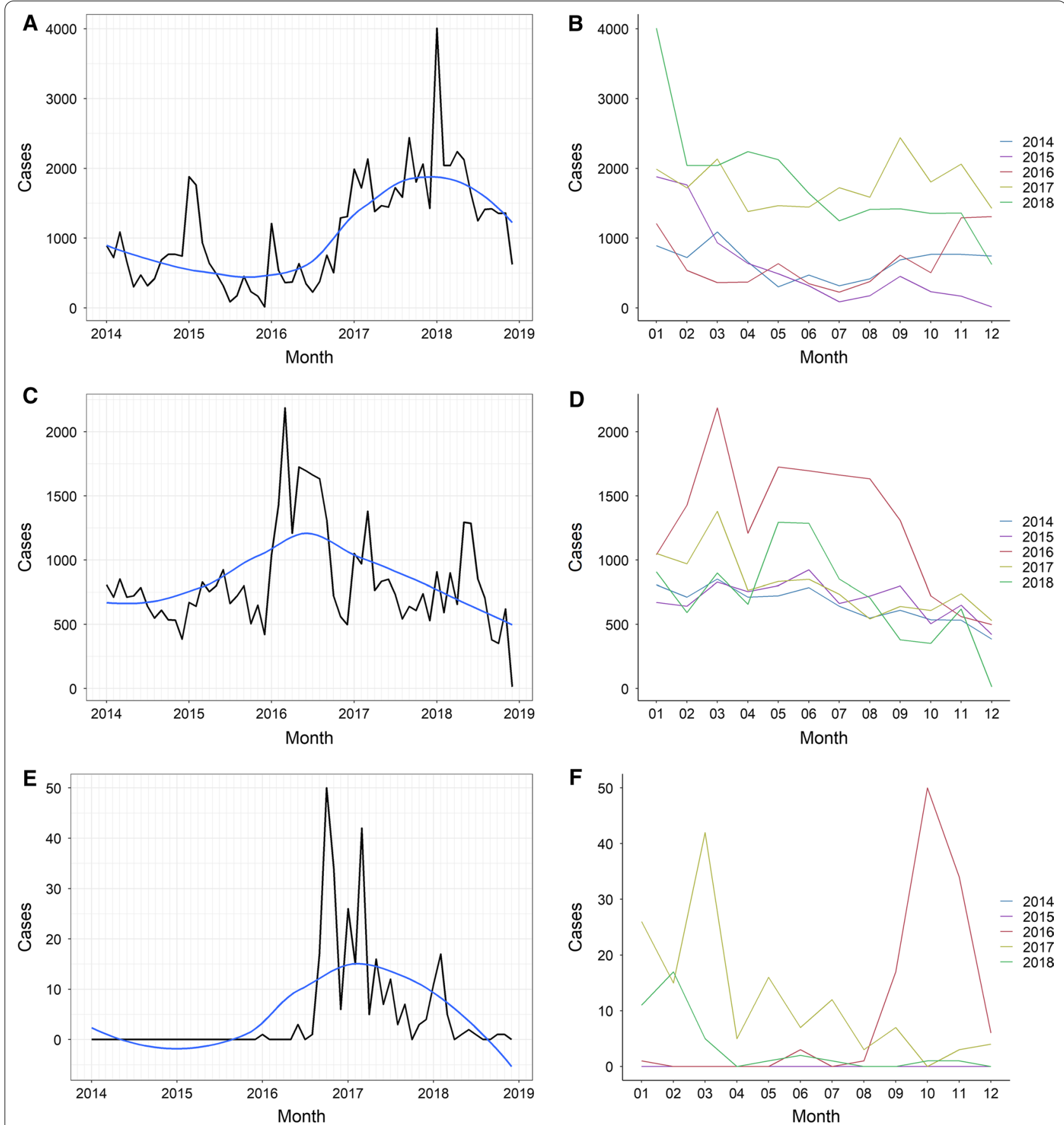

Fig. 2 Monthly malaria cases registered in Amerindian groups of Amazonas, Bolivar and Sucre states, Venezuela, 2014-2018. Monthly cases registered between 2014 and 2018 in Amazonas (A), Bolívar (C) and Sucre (E), and aggregated cases per month and year in the three states (B, D, and $\mathbf{F}$, respectively). The blue line in the panels on the left represents the LOESS curve

Amazonas, due to the lack of adequate parish-level data in this state.

The Atures municipality accounted for most cases in Amazonas (44.1\% in 2014, and 67.5\% in 2018). Yet, Moran's I showed no significant clustering either year.
The Getis-Ord analysis, however, revealed a low-significance hot spot (confidence 90\%) in Atures (Fig. 4A, B).

In Bolivar, the Moran's I was positive and statistically significant in 2014 $(I=0.19, p=0.006)$ and $2018(I=0.17$, $p=0.006)$ indicating stable clustering of cases. This was 
Table 2 Cumulative incidence of malaria among indigenous and non-indigenous groups in Amazonas, Bolivar and Sucre states, Venezuela, 2014-2018

\begin{tabular}{|c|c|c|c|c|c|c|c|}
\hline Year & Cases-i & Est. Pop-i & API-i & Cases non-i & Est. Pop non-i & API non-i & RR \\
\hline \multicolumn{8}{|c|}{ Amazonas } \\
\hline 2014 & 7852 & 82,800 & 94.83 & 3512 & 90,344 & 38.87 & *2.44 \\
\hline 2015 & 7164 & 85,082 & 84.20 & 11,477 & 92,921 & 123.51 & ${ }^{*} 0.68$ \\
\hline 2016 & 7942 & 87,427 & 90.84 & 17,009 & 95,481 & 178.14 & $*^{*} 0.51$ \\
\hline 2017 & 21,187 & 89,837 & 235.84 & 45,113 & 98,015 & 460.27 & $*^{*} 0.51$ \\
\hline 2018 & 21,530 & 92,313 & 233.23 & 26,283 & 100,522 & 261.47 & ${ }^{*} 0.89$ \\
\hline \multicolumn{8}{|l|}{ Bolivar } \\
\hline 2014 & 7854 & 57,451 & 136.71 & 67,089 & $1,665,910$ & 40.27 & *3.39 \\
\hline 2015 & 8387 & 58,404 & 143.60 & 98,466 & $1,693,846$ & 58.13 & $*^{*} 2.47$ \\
\hline 2016 & 15,676 & 59,372 & 264.03 & 161,943 & $1,721,527$ & 94.07 & $*^{*} 2.81$ \\
\hline 2017 & 9649 & 60,357 & 159.87 & 251,673 & $1,748,949$ & 143.90 & *1.11 \\
\hline 2018 & 8565 & 61,357 & 139.59 & 242,801 & $1,776,128$ & 136.70 & $* 1.02$ \\
\hline \multicolumn{8}{|l|}{ Sucre } \\
\hline 2014 & 0 & 23,256 & 0.00 & 922 & 988,415 & 0.93 & 0 \\
\hline 2015 & 0 & 23,615 & 0.00 & 3208 & $1,003,939$ & 3.20 & 0 \\
\hline 2016 & 112 & 23,978 & 4.67 & 20,821 & $1,019,515$ & 20.42 & ${ }^{*} 0.23$ \\
\hline 2017 & 140 & 24,348 & 5.75 & 61,747 & $1,035,140$ & 59.65 & ${ }^{*} 0.10$ \\
\hline 2018 & 39 & 24,723 & 1.58 & 67,992 & $1,050,722$ & 64.70 & ${ }^{*} 0.02$ \\
\hline
\end{tabular}

Spatial autocorrelation and clustering

Est. Pop Estimated population, API Annual parasite index, $i$ Indigenous people, Non-i Non-Indigenous people (cases per 1000 people at risk), RR Risk ratio indigenous/ non-indigenous

Z test for significance: ${ }^{*} \mathrm{p}<0.05$

reflected in the hot spot analysis: In 2014, two highly significant (confidence 99\%) hot spots were seen in Aripao (Sucre municipality) and Barceloneta (Angostura municipality). Hot spots of lower significance (confidence 90\%) were seen in Guaniamo (Cedeño), Gran Sabana and Ikabaru (Gran Sabana municipality, Fig. 4C, D). New highsignificance clusters appeared in the entire Gran Sabana municipality in 2018. The central northern region of the state remained a high-significance cold spot during the entire study period.

The situation in Sucre state was only compared to 2016, due to the absence of cases in the two previous years. No significant clusters were identified via Moran's I analysis. The Getis-Ord's Gi* revealed highly significant hot spots in Union in 2016 and 2018 (Benitez municipality), and Romulo Gallegos (Andrés Eloy Blanco municipality) in 2018.

The full results of the Getis-Ord's analysis can be seen in Additional file 4.

\section{Proportion of Plasmodium species and risk factors associated to Plasmodium falciparum infection}

Most infections were caused by Plasmodium vivax: 85,124 (73.3\%), Plasmodium falciparum: 25,201 (21.7\%), or both: 5726 (4.9\%). Plasmodium malariae was only identified in 46 patients (0.04\%), from eight ethnic groups, all of them from Amazonas, and mostly infected in Alto Orinoco (31 cases), and Manapiare (8 cases). The Yanomami accounted for $58.7 \%$ of all Plasmodium. malariae cases. While Plasmodium vivax was the dominant species in all the states, the proportion of Plasmodium falciparum cases in Amazonas and Bolivar (22\% and $21.4 \%$, respectively) was more than twice that in Sucre state $\left(8.6 \%, \mathrm{X}^{2}=35.82 \mathrm{df}=2, p<0.01\right)$.

The proportion of patients with Plasmodium falciparum or mixed infection was also higher in two ethnic groups: the Hoti (42.9\%) and the Yanomami (41.5.\%), compared to the rest of the indigenous population (26.1\%, $\mathrm{X}^{2}=128.30, \mathrm{df}=1, \quad p<0.01$ and $\mathrm{X}^{2}=380.83$, $\mathrm{df}=1, p<0.01$, respectively).

To evaluate possible reasons behind this difference, the odds ratios (OR) for Plasmodium falciparum vs. Plasmodium vivax infection were calculated considering ethnic group, and other available variables such as occupation, gender, age group, and state of infection, results are summarized in Table 3. Plasmodium malariae and mixed infections were excluded from the analysis.

Data on occupation was only recorded in $40.9 \%$ of the 110,325 patients with either Plasmodium falciparum, or Plasmodium vivax infection, most of which worked in the commercial and services branch of the economy $(10.3 \%)$, followed by students $(9.9 \%)$, miners $(9.8 \%)$, and 

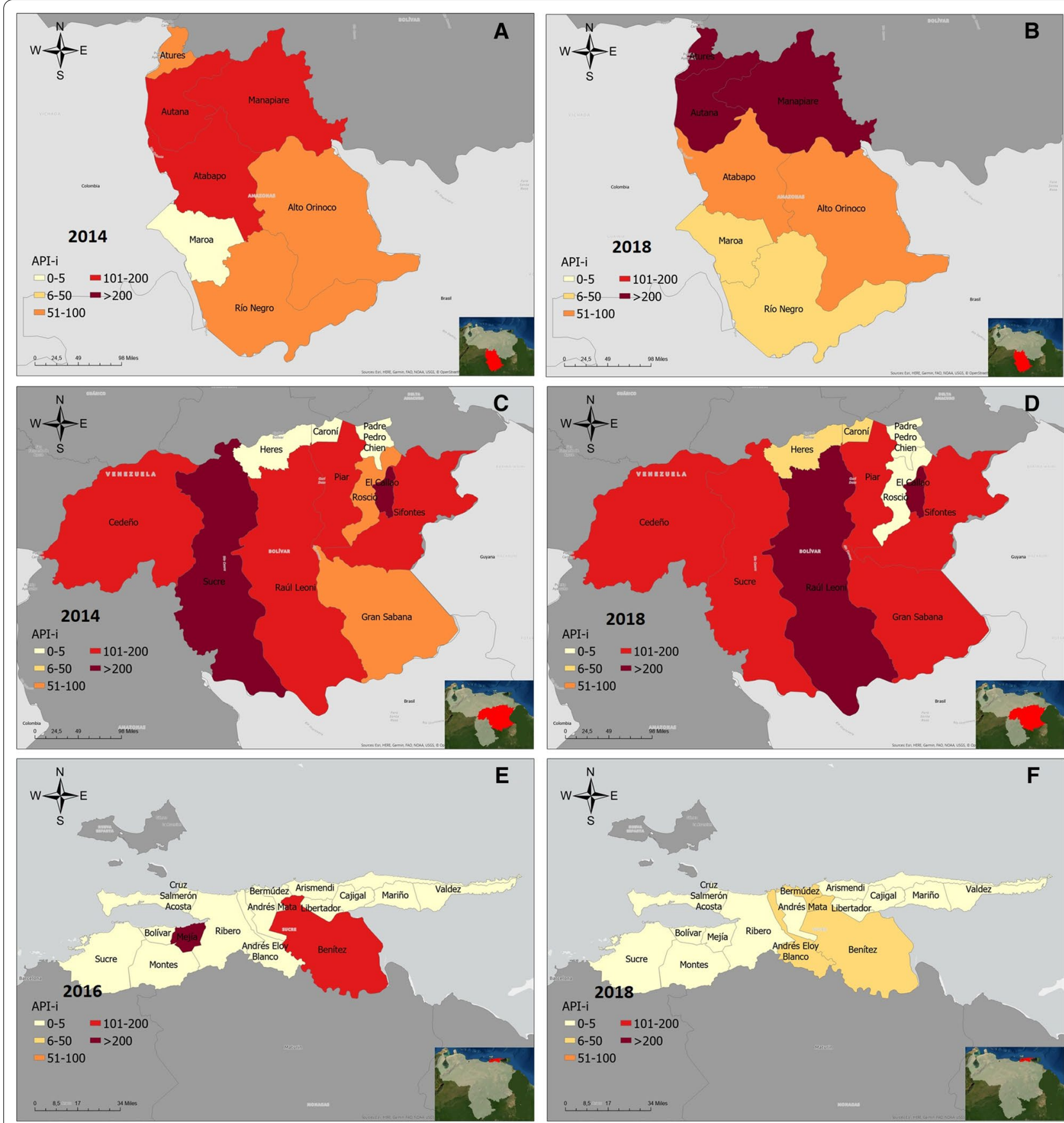

Fig. 3 Evolution of malaria incidence in Amerindian groups of Amazonas, Bolivar and Sucre states, Venezuela, 2014 and 2018. Annual Parasite Index among indigenous patients (API-i) in Amazonas (A, B), Bolivar (C, D), and Sucre (E, F). Panels on the left represent 2014 data (except Sucre), panels on the right, 2018

those working in agriculture (3.4\%). The remaining $8.2 \%$ of all patients with information on occupation worked in diverse areas that were included in the group "others". Compared to this group, miners had a small, but significantly higher OR for Plasmodium falciparum infection (1.09, CI 1.01-1.18, $p=0.03)$.

Odds ratios for Plasmodium falciparum infection increased significantly with age. Compared to children 


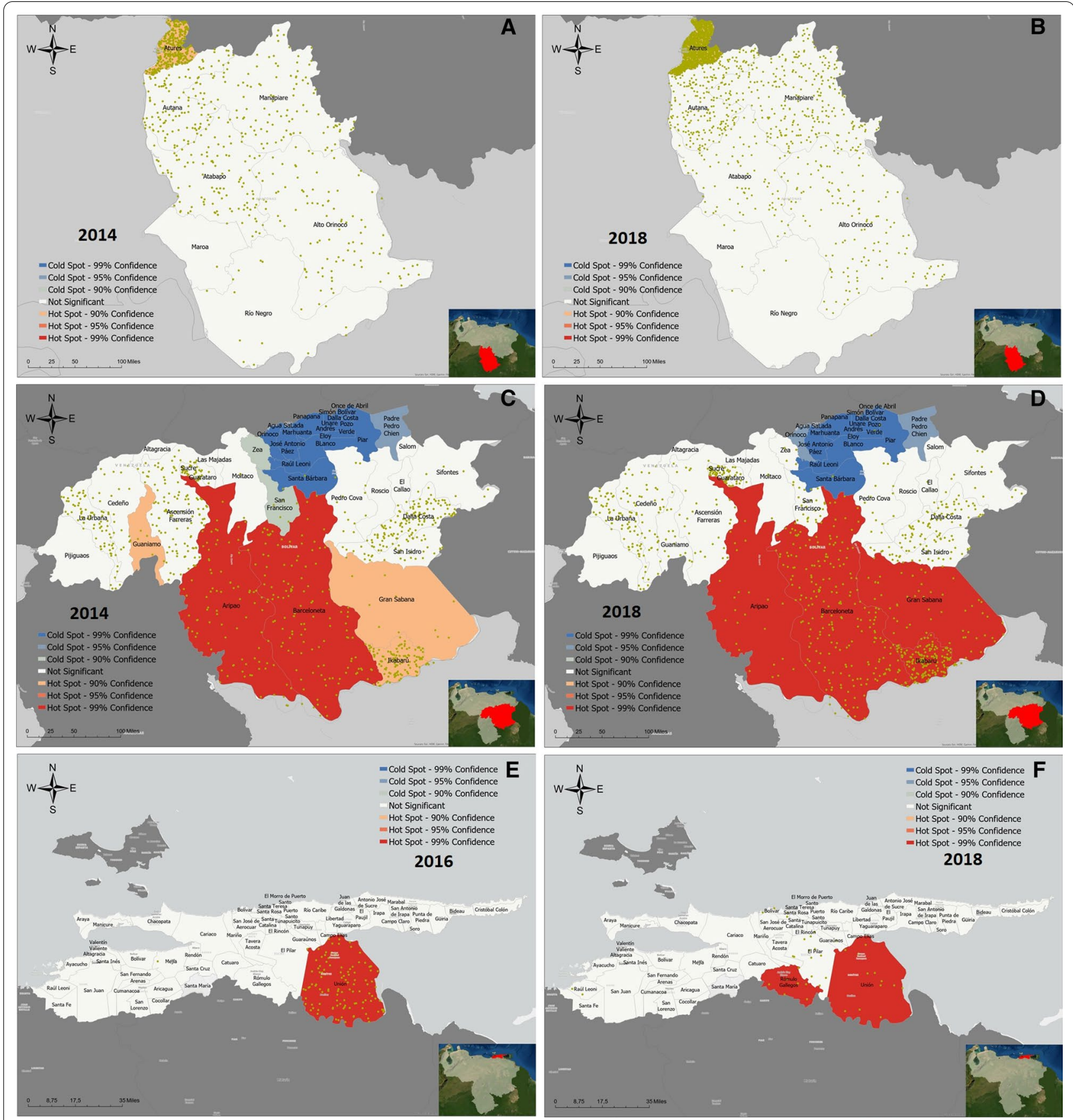

Fig. 4 Evolution of clustering of malaria cases diagnosed among indigenous groups of Amazonas, Bolivar, and Sucre states, Venezuela, $2014-2018$. Burden hot and cold spots detected in Amazonas (A, B), Bolivar (C, D) and Sucre (E, F). Panels on the left represent 2014 data, panels on the right, 2018. Data of 2016 is not shown, except for Sucre, where no cases were registered in 2014. Each dot represents 10 cases of malaria in indigenous people (Amazonas and Bolivar) or 1 case (Sucre). Confidence: $99 \%(p<0.01), 95 \%(0.05>p>0.01), 90 \%(0.1>p>0.05)$

under 5 years, patients over 65 had the highest ratio
(OR: 2.08, CI 1.85-2.33, $p<0.01$ ). Similarly, odds ratios were also considerably higher for the Hoti (OR: 3.33, CI $2.89-3.84, p<0.01$ ), the Yanomami (OR: $3.08, \mathrm{CI}$ 
Table 3 Univariate and multivariable analysis of the odds ratios for Plasmodium falciparum infection among indigenous groups of Amazonas, Bolivar and Sucre states, Venezuela, 2014-2018

\begin{tabular}{|c|c|c|c|c|c|c|c|c|c|c|}
\hline \multirow[t]{2}{*}{ Occupation } & \multirow[t]{2}{*}{$P v$} & \multirow[t]{2}{*}{$P f$} & \multicolumn{4}{|l|}{ Univariate } & \multicolumn{4}{|c|}{ Multivariable } \\
\hline & & & $\mathrm{OR}(\mathrm{Pf} / \mathrm{Pv})$ & $\mathrm{Cl}$ & & $p$ value & $\mathrm{OR}(\mathrm{Pf} / \mathrm{Pv})$ & $\mathrm{Cl}$ & & $p$ value \\
\hline Mining & 7763 & 2656 & 1.44 & 1.35 & 1.54 & $<0.01$ & 1.09 & 1.01 & 1.18 & 0.03 \\
\hline Agriculture & 2951 & 886 & 1.26 & 1.15 & 1.39 & $<0.01$ & 0.82 & 0.74 & 0.91 & $<0.01$ \\
\hline Commerce & 8371 & 2873 & 1.45 & 1.35 & 1.55 & $<0.01$ & & & & \\
\hline Student & 8391 & 2257 & 1.13 & 1.06 & 1.21 & $<0.01$ & & & & \\
\hline Others & 7268 & 1726 & 1.00 & & & & & & & \\
\hline \multicolumn{11}{|l|}{ Age group } \\
\hline $5-14$ & 23,101 & 5619 & 1.02 & 0.97 & 1.07 & 0.50 & 1.08 & 1.02 & 1.15 & 0.01 \\
\hline $15-29$ & 28,739 & 8893 & 1.30 & 1.23 & 1.36 & $<0.01$ & 1.47 & 1.39 & 1.56 & $<0.01$ \\
\hline $30-64$ & 21,127 & 7565 & 1.50 & 1.43 & 1.58 & $<0.01$ & 1.75 & 1.64 & 1.85 & $<0.01$ \\
\hline $65+$ & 1307 & 550 & 1.76 & 1.58 & 1.96 & $<0.01$ & 2.07 & 1.85 & 2.32 & $<0.01$ \\
\hline $0-4$ & 10,424 & 2489 & 1.00 & & & & & & & \\
\hline \multicolumn{11}{|l|}{ Gender } \\
\hline Female & 39,443 & 11,876 & 1.03 & 1.00 & 1.06 & 0.03 & 1.04 & 1.01 & 1.08 & 0.01 \\
\hline Male & 45,681 & 13,325 & 1.00 & & & & & & & \\
\hline \multicolumn{11}{|l|}{ Ethnic group } \\
\hline Pemon & 22,002 & 6633 & 1.19 & 1.12 & 1.26 & $<0.01$ & 1.17 & 1.09 & 1.25 & $<0.01$ \\
\hline Jivi & 21,332 & 6701 & 1.24 & 1.17 & 1.32 & $<0.01$ & 1.29 & 1.22 & 1.37 & $<0.01$ \\
\hline Yekuana & 7804 & 2328 & 1.18 & 1.10 & 1.26 & $<0.01$ & 1.21 & 1.13 & 1.30 & $<0.01$ \\
\hline Wotjuja & 14,640 & 3429 & 0.93 & 0.87 & 0.99 & 0.02 & & & & \\
\hline Kurripaco & 3591 & 812 & 0.89 & 0.82 & 0.98 & 0.02 & 0.87 & 0.79 & 0.96 & $<0.01$ \\
\hline Eñepa & 2335 & 946 & 1.60 & 1.46 & 1.75 & $<0.01$ & 1.76 & 1.59 & 1.94 & $<0.01$ \\
\hline Piapoko & 2500 & 712 & 1.13 & 1.02 & 1.24 & 0.02 & 1.20 & 1.09 & 1.33 & $<0.01$ \\
\hline Yanomami & 1875 & 1248 & 2.63 & 2.41 & 2.87 & $<0.01$ & 3.08 & 2.81 & 3.38 & $<0.01$ \\
\hline Hoti & 538 & 389 & 2.86 & 2.48 & 3.29 & $<0.01$ & 3.33 & 2.89 & 3.84 & $<0.01$ \\
\hline Kubeo & 25 & 3 & 0.47 & 0.14 & 1.57 & 0.22 & & & & \\
\hline Warao & 325 & 48 & 0.58 & 0.43 & 0.79 & $<0.01$ & & & & \\
\hline Warekena & 255 & 44 & 0.68 & 0.49 & 0.94 & 0.02 & 0.67 & 0.48 & 0.93 & 0.02 \\
\hline Akawayo & 791 & 108 & 0.54 & 0.44 & 0.66 & $<0.01$ & 0.46 & 0.38 & 0.57 & $<0.01$ \\
\hline Other & 7111 & 1800 & 1.00 & & & & & & & \\
\hline \multicolumn{11}{|l|}{ State } \\
\hline Amazonas & 48,894 & 14,452 & 2.92 & 1.93 & 4.41 & $<0.01$ & 2.52 & 1.49 & 4.29 & $<0.01$ \\
\hline Bolivar & 35,983 & 10,724 & 2.94 & 1.95 & 4.45 & $<0.01$ & 2.31 & 1.38 & 3.87 & $<0.01$ \\
\hline Sucre & 247 & 25 & 1.00 & & & & & & & \\
\hline
\end{tabular}

Pf, Plasmodium falciparum; Pv, Plasmodium vivax; OR, Odd ratios calculated via binomial logistic regression; $\mathrm{Cl}, 95 \%$ confidence intervals; $\mathrm{p}$ values calculated via Wald's test

$2.81-3.38, p<0.01)$, and to a lesser extent, the Eñepa $(1.76$, CI $1.59-1.94, p<0.01)$ as well as for patients from Amazonas (OR: 2.52. CI 1.49-4.29, $p<0.01$ ), and Boli$\operatorname{var}$ (OR: 2.31, CI 1.38-3.87, $p<0.01$ ).

\section{Discussion}

Malaria seems to affect Amerindian patients similarly regardless of sex, with most cases concentrating in patients between 5 and 24 years (50.3\%). Symptomatic disease reduces in older groups, as the proportion of cases in male patients increases, likely due to a higher exposure to infectious bites.

The number of cases of malaria among Amerindian patients per 1000 people at risk (API-i) increased between 2014 and 2018 in all the studied states, mainly driven by a surge in cases in Amazonas, and to a lesser extent in Bolivar, which was particularly clear between 2014 and 2017. From that point onwards, cases in these two states have stabilized, and even returned to levels similar to those of 2014 in the case of Bolivar. This probably responds to recent efforts carried out by local and 
international actors, which have concentrated on this State.

Furthermore, compared to that of the non-indigenous population, malaria risk among Amerindian groups has reduced since 2014, indicating that the current national epidemic is mostly driven by non-indigenous patients.

There are obvious differences in risk between different municipalities, with API-is in Manapiare (Amazonas), El Callao, and Angostura (Bolivar) being particularly high. However, the municipal API-i should be interpreted carefully, as the malaria risk of communities with a small projected indigenous population is likely overestimated. Population estimates used in this study are entirely based on census data, which does not include transient inhabitants who are living and working in the study area. This is a major limitation of this study, as the actual at-risk population in these places is certainly larger than estimated. Places like El Callao (Bolívar), where registered malaria cases exceed the projected indigenous population, leading to abnormally large API-is, are a good example of this. A full list of the estimated indigenous populations of individual municipalities can be found in the Additional file 3. To address this issue and prioritize areas for eventual interventions, the cluster analysis was carried out with individual cases, rather than calculated API-is.

In Amazonas state, although most cases originated in Atures (where the only large town in the state is located), the Getis-Ord's Gi* statistic only revealed low-significance hotspots both in 2014 and 2018. This suggests that cases are only weakly clustered, and more distributed throughout the north of the state (Fig. 4). Although the lack of parish-level data in Amazonas limits the interpretation of these results, this might be partially influenced by the Orinoco Mining Arc, a large-scale mining project involving areas along the border between Bolivar and Amazonas [22, 23]. Increased domestic migration from other states due to mining might also help explain the reduction in the relative risk of Amerindian groups, compared to non-indigenous patients in this state.

In Bolivar State, clustering was consistently identified south of the state. The southeast of Bolivar comprises the historical location of the Pemon, the largest single ethnic group identified in this study. Illegal mining by this and other groups in protected areas of Canaima National Park [24], mostly located in the Gran Sabana municipality, and along the Caroní River (the natural border between Barceloneta and Gran Sabana parishes), is well reported [22, 24, 25]. Smaller-scale illegal mining in the remote Upper Caura river basin (Aripao parish), and the Paragua river (Barceloneta parish), mostly conducted by local Amerindian groups like the Yekuana, has also been documented [25-27], and likely influences the clustering of malaria among Amerindian communities in the south of Bolivar. The highly significant cold spots identified in the north of the state respond to the small proportion of indigenous population in the area.

Surprisingly, the Sifontes municipality, recently identified as the most important cluster of malaria transmission in the Americas [2], was not found to be a significant hot spot for Amerindian groups. While this might reflect a predominance of mining activity by the Pemon, the Yekuana, and other groups in different areas, further research is needed to confirm this finding and understand the reasons behind it.

If malaria among Amerindian groups indeed presents a different geographic pattern, interventions in locations apart from Sifontes will be key to curb the impact of the epidemic. Geolocation data used in this work comes from interrogation of confirmed cases by Ministry of Health staff. Therefore, although this data can provide a general picture of the spatial distribution of infections, global positioning system (GPS) data should be obtained from active case detection campaigns carried out in parishes identified as hot spots, to objectively confirm these findings, and guide future interventions.

Cases in Sucre represented only $0.25 \%$ of all cases analysed, in accordance with its comparatively small and mostly urban indigenous population, and less intense transmission. Hot spots in this state matched areas of known high incidence [16], where indigenous patients have probably benefited more from interventions currently in place, explaining the reduction seen in 2018.

All data used in this study came from passive detection of symptomatic malaria cases. Therefore, annual cumulative incidence is likely underreported, as some patients will develop asymptomatic infection, and many more will not seek medical attention at all. The effect of this underreporting heterogeneously impacts the interpretation of these results, as it is probably more important among isolated groups, (such as the Yanomami, the Hoti, or the Yekuana) than others that are better connected to the national health infrastructure (Pemon) or live in a predominantly urban environment (patients infected in the north of Bolivar, and those living in Sucre state). Similarly, cases originated in these states, but reported elsewhere, were not included in the analysis.

As only new cases meeting the Ministry of Health's definition are included in the datasets, duplicated cases are generally excluded and stored separately by Ministry staff, which reduces the potential impact of misreporting.

Seasonality was only observed in Bolivar, but this has not been described in the general population [28]. However, these studies date from 2010, and malaria cases in this state are influenced by the El Niño Southern 
Oscillation phenomenon [28], which was particularly intense in the 2015-2016 period [29] and might have influenced the large peak of cases in the early months of 2016 and 2017. The exposure of the indigenous population to infectious bites might also change more markedly during the year due to specific cultural or economic factors beyond the scope of this study.

The presence of Plasmodium malariae exclusively in patients from Amazonas, and mostly among the Yanomami, matches previous reports that link this species to remote areas of the state [30]. The Hoti and the Yanomami were also found to have significantly higher odds for Plasmodium falciparum infection. Similar to Plasmodium malariae, Plasmodium falciparum is more prevalent in the rainforest of Amazonas than in the rest of the country [31]. Previous works suggest that the higher prevalence of Plasmodium falciparum and Plasmodium malariae in the Alto Orinoco region might be explained by a longer life expectancy of local Anopheles darlingi mosquito populations [31]. This might in turn reflect flaws in local vector control strategies, and the lack of targeted measures that adapt to the particular living conditions of the Yanomami and the Hoti, such as their nomadic habits, and housing materials that render IRS and bed nets ineffective [31]. Insecticide-treated hammocks have proven a useful alternative in this context [13].

Although miners presented higher odds for Plasmodium falciparum infection too, the difference was very small and might be more related to their increased exposure to infectious bites, than to a higher Plasmodium falciparum prevalence in Venezuelan mines, which has not been described [12]. Furthermore, occupation data was only available for 45,142 patients $(40.9 \%$ of the total analysed), complicating the interpretation of these results. Increased exposure to infectious bites is probably also the reason for higher odds in older age groups.

\section{Conclusion}

Malaria incidence among Amerindian groups has increased since 2014, although the trend has partly reversed in the last two years. Clustering of malaria cases is particularly clear in Bolivar, where it is likely being influenced by mining, necessitating a wider deployment of targeted interventions. These interventions should initially prioritize the Hoti, Yanomami, and Eñepa, due to their increased risk of $P$. falciparum infection, associated with severe malaria.

\section{Abbreviations}

API-i: Annual Parasite index among Amerindian groups (number of cases of malaria reported in Amerindian patients per 1000 Amerindian people); GPS: Global positioning system; NGO: Non-government organization.

\section{Supplementary Information}

The online version contains supplementary material available at https://doi. org/10.1186/s12936-021-03819-7.

Additional file 1. Ethnic groups included in registries of the Venezuelan Ministry of Health (MPPS).

Additional file 2. Malaria incidence in indigenous patients and relative risk compared to non-indigenous population.

Additional file 3. Estimated indigenous population and growth rates.

Additional file 4. Getis-Ord's Gi* Analysis for clustering of malaria cases (2014-2018).

Additional file 5. Seasonal distribution of malaria cases diagnosed among Amerindian patients in Amazonas, Bolivar and Sucre between 2014 and 2018.

Acknowledgements

The authors would like to thank Dr. David Conway, Dr. Mariapía Bevilacqua, Dr. Eglee Zent, and Juliane Chaccour MSc, for their technical advice.

\section{Authors' contributions}

Conceptualization: JCG, LV. Writing —original draft: JCG, LV, CCh. Data management and processing: JCG, JM, MV. Writing-review \& editing: all authors contributed, reviewed the last draft. All authors read and approved the final manuscript.

\section{Funding}

CCh received salary support from Unitaid through the BOHEMIA grant to ISGlobal. ISGlobal acknowledges support from the Spanish Ministry of Science and Innovation through the "Centro de Excelencia Severo Ochoa 2019-2023" Program (CEX2018-000806-S), and support from the Generalitat de Catalunya through the CERCA Program. The funding sources had no role on the design, analysis or decision to publish the results of this study. No funding was specifically allocated to this project.

\section{Availability of data and materials}

The datasets used for this project are available from the corresponding author on reasonable request.

\section{Declarations}

Ethics approval and consent to participate

This project was approved by the independent ethics committee of the Venezuelan National Bioethics Center (Reference number: CIBI-CENABI-04/2020), and the MSc Research Ethics Committee at the London School of Hygiene and Tropical Medicine (Reference number: 21868).

Consent for publication

Not applicable.

\section{Competing interests}

The authors declare no conflict of interest.

\section{Author details}

${ }^{1}$ Área de Enfermedades Infecciosas, Clínica Universidad de Navarra,

31008 Pamplona, Spain. ${ }^{2}$ Instituto de Inmunología Clínica, Universidad de Los Andes, Mérida, Venezuela. ${ }^{3}$ ISGlobal, Hospital Clínic - Universitat de Barcelona, Barcelona, Spain. ${ }^{4}$ Ifakara Health Institute, Ifakara, United Republic of Tanzania. ${ }^{5}$ Centro de Investigación de Campo "Francesco Vitanza", Instituto de Altos Estudios "Dr, Arnoldo Gabaldon", Tumeremo, Venezuela. ${ }^{6}$ Asociación Civil Impacto Social (ASOCIS), Tumeremo, Venezuela. ${ }^{7} \mathrm{Global}$ Development One, Silver Spring, MD, USA.

Received: 1 March 2021 Accepted: 15 June 2021

Published online: 26 June 2021 


\section{References}

1. WHO. World Malaria Report. Geneva: World Health Organization; 2020

2. Grillet ME, Moreno JE, Hernández JV, Vincenti-González MF, Noya O, Tami A, et al. Malaria in Southern Venezuela: the hottest hotspot in Latin America. PLoS Negl Trop Dis. 2021;15:e0008211.

3. Grillet ME. Factors associated with distribution of Anopheles aquasalis and Anopheles oswaldoi (Diptera: Culicidae) in a malarious area, northeastern Venezuela. J Med Entomol. 2000;37:231-8.

4. MPPS. Boletín Epidemiológico \#52 Caracas, Venezuela: Ministerio del Poder Popular para la Salud; 2016. https://www.ovsalud.org/publicacio nes/documentos-oficiales/boletin-epidemiologico-2016/. Accessed 01 June 2020.

5. INE. XIV Censo Nacional de Población y Vivienda 2011. Caracas: Instituto Nacional de Estadística; 2014

6. Logros del Estado Venezolano en Materia de Salud y Pueblos Indígenas Geneva: Permanent Mission of Venezuela before the United Nations; 2016. https://www.ohchr.org/Documents/Issues/IPeoples/EMRIP/Health/ Venezuela.pdf. Accessed 06 May 2021.

7. Bevilacqua M, Medina DA, Cárdenas L, Rubio-Palis Y, Moreno J, Martínez A. Orientaciones para fortalecer el programa de malaria en zonas remotas con población indígena en el Caura. Venezuela Bol Malariol Salud Ambient. 2009;49:53-72

8. Grenfell P, Fanello Cl, Magris M, Goncalves J, Metzger WG, Vivas-Martínez $S$, et al. Anaemia and malaria in Yanomami communities with differing access to healthcare. Trans R Soc Trop Med Hyg. 2008;102:645-52.

9. Bevilacqua M, Rubio-Palis Y, Medina DA, Cárdenas L. Malaria control in Amerindian communities of Venezuela: strengthening ecohealth practice throughout conservation science and capability approach. EcoHealth. 2015:12:253-66.

10. Mosnier E, Roux E, Cropet C, Lazrek Y, Moriceau O, Gaillet M, et al. Prevalence of Plasmodium spp. in the Amazonian border context (French Guiana-Brazil): associated factors and spatial distribution. Am J Trop Med Hyg. 2020;102:130-41.

11. Bevilacqua M, Rubio-Palis Y. Acciones necesarias ante la epidemia de malaria en la Guayana indígena. Bol Malariol Salud Ambient. 2018;58:2-15.

12. Douine $M$, Lambert $Y$, Musset $L$, Hiwat $H$, Blume LR, Marchesini P, et al. Malaria in gold miners in the Guianas and the Amazon: current knowledge and challenges. Curr Trop Med Rep. 2020;7:37-47.

13. Magris M, Rubio-Palis Y, Alexander N, Ruiz B, Galván N, Frias D, et al. Community-randomized trial of lambdacyhalothrin-treated hammock nets for malaria control in Yanomami communities in the Amazon region of Venezuela. Trop Med Int Health. 2007;12:392-403.

14. MPPS. Boletín Epidemiológico Semana 53 Caracas, Venezuela: Ministerio del Poder Popular para la Salud; 2014. https://www.ovsalud.org/publi caciones/documentos-oficiales/boletin-epidemiologico-2014/. Accessed 01 June 2020

15. MPPS. Boletín Epidemiológico Semana 52 Caracas, Venezuela: Ministerio del Poder Popular para la Salud; 2015. https://www.ovsalud.org/publi caciones/documentos-oficiales/boletin-epidemiologico-2015/. Accessed 01 June 2020
16. Malaria, IPA, surveillance, falciparum, vivax, morbidity, mortality, plasmodium, risk, statistics, health, indicators. Regional Malaria Program HDS/ CD/Malaria. Pan American Health Organization; 2010. http://ais.paho.org/ phip/viz/malaria_surv_indicators_popup.asp. Accessed 01 June 2020.

17. MPPS. Programa Nacional de Eliminación de Malara. Pautas de tratamiento en casos de malaria. Caracas: Ministerio del Poder Popular para la Salud; 2017.

18. CEPAL. Estadísticas e Indicadores Sociales: Comisión Económica para América Latina y el Caribe; 2020. http://interwp.cepal.org/sisgen/Sisgen MuestraFicha_puntual.asp?indicador=300\&id_estudio=1\&id_aplic acion=1\&idioma=e. Accessed 30 May 2020.

19. Anselin L. Local indicators of spatial association-LISA. Geogr Anal. 1995:27:93-115.

20. Getis A, Ord JK. The analysis of spatial association by use of distance statistics. Geogr Anal. 1992;24:189-206.

21. Tewara MA, Mbah-Fongkimeh PN, Dayimu A, Kang F, Xue F. Small-area spatial statistical analysis of malaria clusters and hotspots in Cameroon; 2000-2015. BMC Infect Dis. 2018:18:636.

22. Rendon M, Sandin L, Fernandez C. Illegal mining in Venezuela: death and devastation in the Amazonas and Orinoco Regions. Washington: Center for Strategic and International Studies; 2020.

23. Capdevilla M. Environmental penal control in Venezuela: Amazonia and the Orinoco Mining Arc. In: The 21st century fight for the amazon: environmental enforcement in the world's bigges rainforest. London: Palgrave Macmillan; 2018. p. 137

24. Bonet NG. Mining against the State? Gold mining and emerging notions of territoriality in Southeastern Venezuela. Bull Latin Am Res. 2020;39:305-18.

25. Minería llegal en la Panamazonía: Red Amazónica de Información Socioambiental Georreferenciada; 2020. https://mineria.amazoniasocioam biental.org/. Accessed 06 May 2021.

26. Angosto-Ferrández LF. Neoextractivism and class formation: lessons from the orinoco mining arc project in Venezuela. Latin Am Perspect. 2019;46:190-211.

27. Lozada JR. The Orinoco Mining Arc: a historical perspective. Gold Bulletin. 2019:52:153-63.

28. Grillet ME, El Souki M, Laguna F, León JR. The periodicity of Plasmodium vivax and Plasmodium falciparum in Venezuela. Acta Trop. 2014;129:52-60.

29. Null J. El Niño and La Niña years and intensities. Based on Oceanic Niño Index. Golden Gate Weather Services; 2020.

30. Cáceres GJL. Epidemiología de malaria por Plasmodium malariae en Venezuela, 1999-2008. Bol Malariol Salud Ambient. 2009;49:303-7.

31. Magris M, Rubio-Palis Y, Menares C, Villegas L. Vector bionomics and malaria transmission in the Upper Orinoco River, Southern Venezuela. Mem Instit Oswaldo Cruz. 2007;102:303-12.

\section{Publisher's Note}

Springer Nature remains neutral with regard to jurisdictional claims in published maps and institutional affiliations.
Ready to submit your research? Choose BMC and benefit from:

- fast, convenient online submission

- thorough peer review by experienced researchers in your field

- rapid publication on acceptance

- support for research data, including large and complex data types

- gold Open Access which fosters wider collaboration and increased citations

- maximum visibility for your research: over 100M website views per year

At $\mathrm{BMC}$, research is always in progress.

Learn more biomedcentral.com/submissions 